\title{
SELECTING ALTERNATIVES FROM SELF-ORGANIZING PRODUCT MAPS FOR PURCHASE DECISION MAKING USING AHP
}

\author{
Kazuhiro Kohara* \\ Department of Electrical, Electronics and Computer Engineering \\ Chiba Institute of Technology \\ Narashino, Japan \\ E-mail: kohara.kazuhiro@it-chiba.ac.jp
}

\begin{abstract}
We previously proposed a method for creating product maps with self-organizing maps (SOM) to be used during purchase decision making. In that study, we first established two class boundaries, which divide the area between the minimum and maximum range of an input feature value into three equal parts. Then, we produced self-organizing product maps using classification data inputs. Finally, we applied our method to five product types and confirmed its effectiveness. In this paper, we propose a method for selecting alternatives from a product map, in which we have located a favorite cluster, and/or from a favorite component map. We then show several examples of selecting alternatives and making decisions using the analytic hierarchy process (AHP).
\end{abstract}

Keywords: marketing decisions, purchase decision making, self-organizing maps, selection of alternatives

\section{Introduction}

We previously proposed a purchase decision making support method (Kohara, and Isomae, 2006) using self-organizing maps (SOM) (Kohonen, 1995) and the analytic hierarchy process (AHP) ((Saaty, 1980), (Kinoshita, 2000)). We also proposed a method for creating product maps with SOM for purchase decision making (Kohara, and Tsuda, 2010). A self-organizing map for PCs sold in 2009 using our classification data inputs is shown in Figure 1. The features of the PCs in clusters N1 to N5 are as shown in Table 1, where the underlined features are indispensable and more than half of the other features are necessary. In this paper, we propose a method for selecting alternatives from a product map.

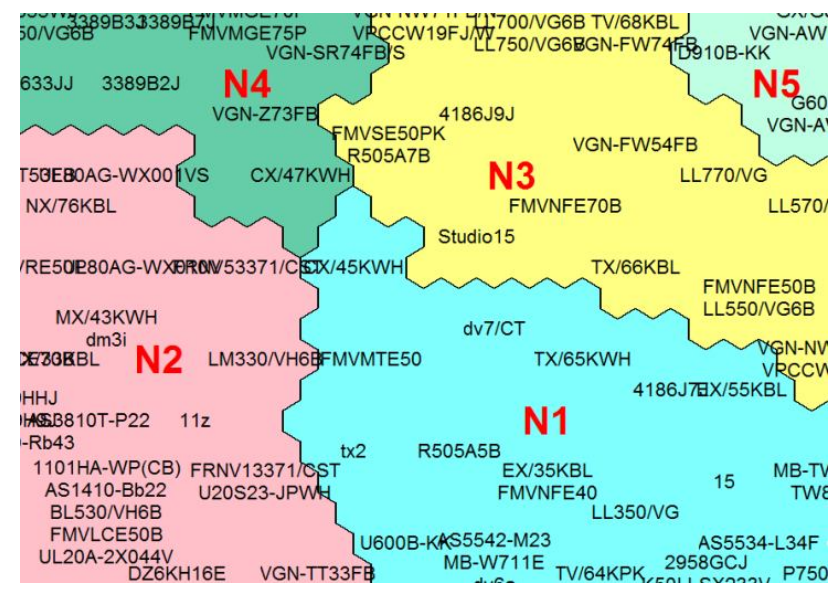

Figure 1. Self-organizing map for PCs sold in 2009 using our classification data inputs.

\footnotetext{
${ }^{*}$ Corresponding author
} 
Table 1. Primary features of PCs sold in 2009 in each cluster.

\begin{tabular}{|l|l|l|r|}
\hline Cluster \# (\# of products) & Features & Primary feature & Accuracy \\
\hline Cluster N1 (24) & $\begin{array}{l}1.74 \text { to 2.26 GHz (CPU), } \\
\text { 248 to 372 GB (HDD), } \\
2.34 \text { to 3.46 kg (weight) }\end{array}$ & $\begin{array}{l}\text { Middle performance, } \\
\text { middle weight }\end{array}$ & $24 / 24$ \\
\hline Cluster N2 (25) & $\begin{array}{l}\text { under 1.73 GHz (CPU), } \\
\text { under 2.33 kg (weight), } \\
\text { under 99,959 yen (price) }\end{array}$ & $\begin{array}{l}\text { Low performance, } \\
\text { light weight, } \\
\text { low price }\end{array}$ & $25 / 25$ \\
\hline Cluster N3 (21) & $\begin{array}{l}\text { over 2.27 GHz (CPU), } \\
\text { over 3 GB (RAM) }\end{array}$ & High performance & $20 / 21$ \\
\hline Cluster N4 (11) & $\begin{array}{l}\text { over 5.0 hours (battery life), } \\
\text { under 2.33 kg (weight) }\end{array}$ & High mobility & $10 / 11$ \\
\hline Cluster N5 (5) & $\begin{array}{l}\text { over 2.27 GHz (CPU), } \\
\text { over 3 GB (RAM), } \\
\text { over 15.6 inches (monitor), } \\
\text { over 154.158 yen (price), } \\
\text { Blu-Ray drive }\end{array}$ & $\begin{array}{l}\text { Highest performance } \\
\text { and high price }\end{array}$ & $4 / 5$ \\
\hline Total (86) & \multicolumn{2}{|c|}{$83 / 86=96.5 \%$} \\
\hline
\end{tabular}

\section{Selecting alternatives from product maps}

Figure 2 shows an example of the relative measurement AHP model created for the task of buying a PC. For the goal on the first level (i.e., the task of buying a PC), four criteria on the second level and five alternatives on the third level were defined. Here, we used the following four criteria: low price, high mobility, high performance, and design preferences. High mobility is defined here as light weight and long battery life. High performance is defined as a combination of high CPU speed, large RAM capacity, large HDD storage capacity and a large monitor.

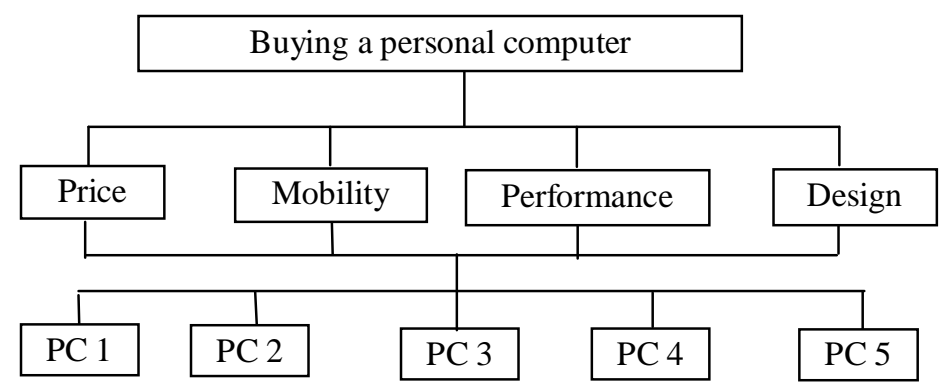

Figure 2. AHP model created for the task of buying a personal computer (PC).

We recommend that consumers select alternatives using the product maps in the following ways: from a favorite cluster and/or from a favorite component map. Here, we propose a method of selecting alternatives from self-organizing product maps. Our outline of the steps is as follows:

\section{Steps for selecting alternatives}

Step 1: Examine the product map and ensure you understand the primary features of the products in each cluster. 
Step 2: Examine the component maps and ensure you understand each component value.

Step 3: Select a favorite cluster and/or a favorite component map. After you select a favorite cluster, go to Step 4. After you select a favorite component map, go to Step 5. After you select a favorite cluster and a favorite component map, go to Step 6.

Step 4: Select alternatives from your favorite cluster. For example, select a favorite product or a favorite brand in your favorite cluster. After you select a favorite product, select alternatives using the neighborhood view function. After you choose a favorite brand, select alternatives from your favorite brand in your favorite cluster.

Step 5: Select alternatives from your favorite component map. For example, choose a favorite product or a favorite brand from your favorite component map. After you choose a favorite product, select alternatives using the neighborhood view function. When you have found a favorite brand, select alternatives from your favorite brand in your favorite component map.

Step 6: Select alternatives that belong to both your favorite cluster and your favorite component map.

\subsection{From a favorite cluster}

Now, let's examine a sample case where a consumer would like to purchase a high performance PC. He first selected five alternatives (see Table 2) using the neighborhood view function of Viscovery SOMine 4.0 software (this function displays all nodes that are topologically similar to a reference node) from a favorite cluster (N3) of a PC map whose primary feature is high performance, as shown in Figure 3. Here, PC 11 (FMVNFE70B) is a favorite PC and a reference node. Accordingly, he selected PC 11 and chose four alternatives using the PC map.

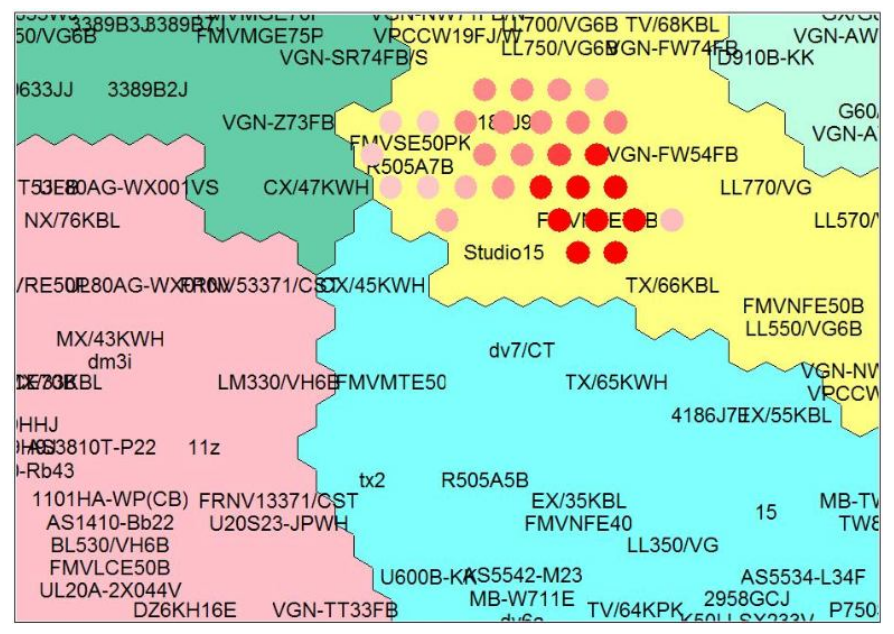

Figure 3. Selection of PC alternatives, using the neighborhood view function, from favorite cluster N3 (high performance).

Table 2. Selection of PC alternatives from favorite cluster N3 (high performance).

\begin{tabular}{|c|c|c|c|c|c|c|c|}
\hline & $\begin{array}{c}\text { CPU } \\
(\mathrm{GHz})\end{array}$ & $\begin{array}{c}\text { RAM } \\
(\mathrm{GB})\end{array}$ & $\begin{array}{c}\text { HDD } \\
(\mathrm{GB})\end{array}$ & $\begin{array}{c}\text { Monitor } \\
\text { (inches) }\end{array}$ & $\begin{array}{c}\text { Weight } \\
(\mathrm{kg})\end{array}$ & $\begin{array}{c}\text { Battery } \\
\text { (hours) }\end{array}$ & $\begin{array}{c}\text { Price } \\
(\text { yen})\end{array}$ \\
\hline PC 11 & 2.53 & 4 & 500 & 15.6 & 2.80 & 2.1 & 129,800 \\
\hline PC 12 & 2.53 & 4 & 500 & 14.1 & 2.50 & 3.9 & 122,280 \\
\hline PC 13 & 2.53 & 4 & 500 & 15.4 & 2.70 & 2.4 & 109,800 \\
\hline PC 14 & 2.53 & 4 & 500 & 16.4 & 3.20 & 3.0 & 141,871 \\
\hline PC 15 & 2.66 & 4 & 500 & 15.6 & 2.75 & 4.0 & 148,799 \\
\hline
\end{tabular}




\subsection{From a favorite component map}

Now, let's examine a sample case where a consumer would like to purchase a PC with a very long battery life. Using the neighborhood view function, he first selected five alternatives (see Table 3) from a favorite component map with battery lives over 8.7 hours, as shown in Figure 4. In the "over 8.7 hours" component map, the red neurons correspond to the over "8.7 hours" class and the blue neurons correspond to the other classes. Here, PC 21 (UL80AG-WX001VS) is a favorite PC and a reference node. Accordingly, he selected PC 21 and chose four alternatives using the component map. Note that users can select more than one favorite component map. For example, if a consumer would like a low price PC with a very long life battery, he can choose to select alternatives from both the low price (under 99,959 yen) and very long battery life (over 8.7 hours) favorite component maps.

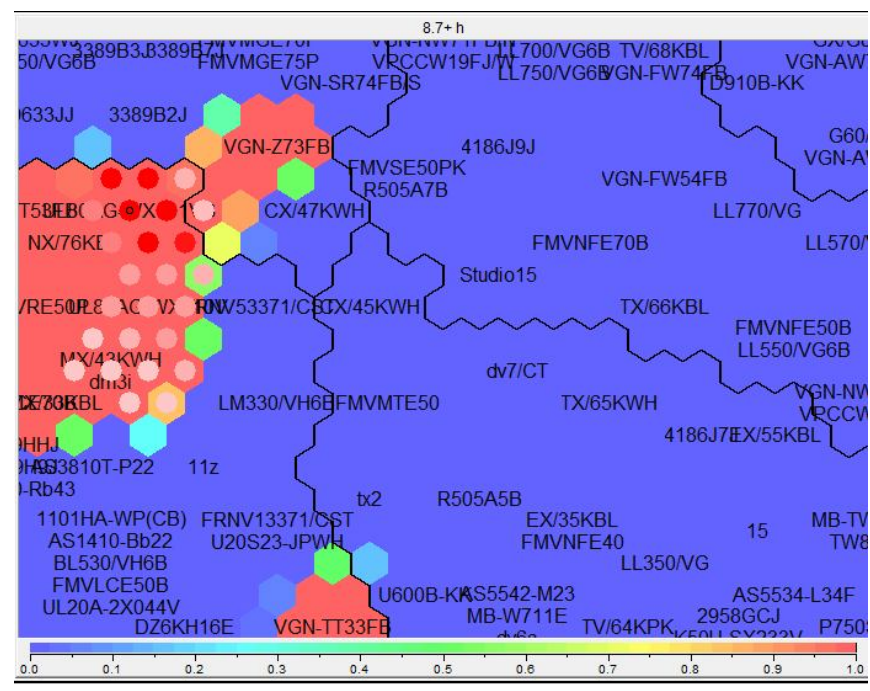

Figure 4. Selection of PC alternatives, using the neighborhood view function, from a favorite component map (very long battery life).

Table 3. Selection of PC alternatives from a favorite component map (very long battery life).

\begin{tabular}{|l|c|c|c|c|c|c|c|}
\hline & $\begin{array}{c}\text { CPU } \\
(\mathrm{GHz})\end{array}$ & $\begin{array}{c}\text { RAM } \\
(\mathrm{GB})\end{array}$ & $\begin{array}{c}\text { HDD } \\
(\mathrm{GB})\end{array}$ & $\begin{array}{c}\text { Monitor } \\
\text { (inches) }\end{array}$ & $\begin{array}{c}\text { Weight } \\
(\mathrm{kg})\end{array}$ & $\begin{array}{c}\text { Battery } \\
\text { (hours) }\end{array}$ & $\begin{array}{c}\text { Price } \\
(\text { yen})\end{array}$ \\
\hline PC 21 & 1.40 & 2 & 320 & 14.0 & 1.98 & 11.4 & 116,819 \\
\hline PC 22 & 1.20 & 2 & 320 & 14.0 & 1.98 & 9.5 & 71,820 \\
\hline PC 23 & 1.40 & 4 & 250 & 11.1 & 1.27 & 10.0 & 134,184 \\
\hline PC 24 & 1.40 & 2 & 250 & 13.3 & 1.76 & 10.5 & 77,060 \\
\hline PC 25 & 1.20 & 2 & 320 & 13.3 & 1.90 & 10.0 & 79,800 \\
\hline
\end{tabular}

\subsection{From a favorite cluster and a favorite component map}

Now, let's examine a case where a consumer would like to purchase a high performance and low price PC. He first selected five alternatives (see Table 4) from a favorite cluster (N3) of a PC map whose primary feature is high performance and a favorite component map whose price is under 99,959 yen, as shown in Figure 5. Red letter PCs (e.g., TX/66KBL and FMVNFE50B) belong to both the favorite component map and to favorite cluster N3. 


\section{K. Kohara}
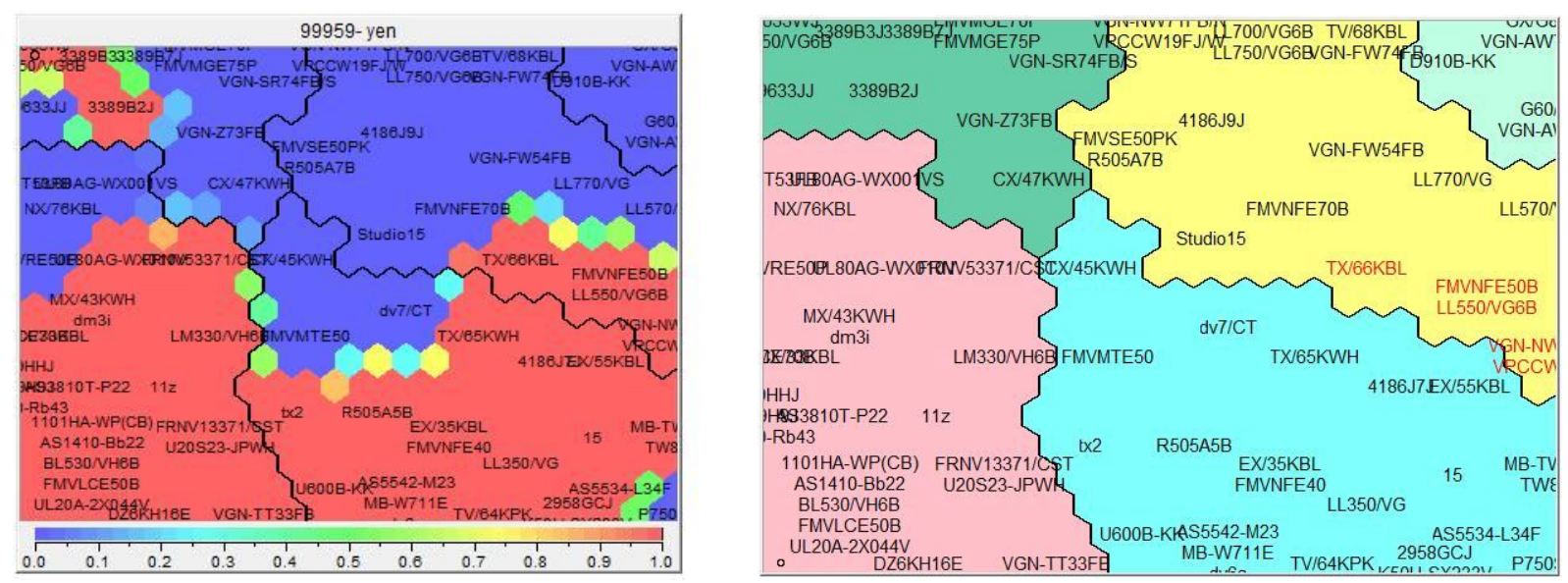

Figure 5. Selection of PC alternatives from favorite component map (low price) (left) and favorite cluster N3 (high performance) (right).

Table 4. Selection of PC alternatives from favorite cluster N3 (high performance) and favorite component map (low price).

\begin{tabular}{|l|c|c|c|c|c|c|}
\hline & $\begin{array}{c}\text { CPU } \\
(\mathrm{GHz})\end{array}$ & $\begin{array}{c}\text { RAM } \\
(\mathrm{GB})\end{array}$ & $\begin{array}{c}\text { Monitor } \\
\text { (inches) }\end{array}$ & $\begin{array}{c}\text { Weight } \\
(\mathrm{kg})\end{array}$ & $\begin{array}{c}\text { Battery } \\
\text { (hours) }\end{array}$ & $\begin{array}{c}\text { Price } \\
\text { (yen) }\end{array}$ \\
\hline PC 31 & 2.53 & 4 & 16.0 & 3.0 & 1.3 & 99,000 \\
\hline PC 32 & 2.53 & 4 & 15.6 & 2.8 & 2.0 & 91,701 \\
\hline PC 33 & 2.53 & 4 & 15.6 & 3.1 & 1.4 & 93,990 \\
\hline PC 34 & 2.53 & 4 & 15.6 & 2.7 & 3.5 & 95,000 \\
\hline PC 35 & 2.53 & 4 & 14.0 & 2.4 & 3.0 & 98,898 \\
\hline
\end{tabular}

\section{Purchase decision making with AHP}

We then applied AHP to the task of buying a PC, as shown in Figure 2. Five alternatives are shown in Table 2. The pair comparison matrix among four criteria considered by the author is shown in Table 5 . For example, price is significantly more important than mobility, while performance is significantly more important than design. As a result, it can be seen that performance is the most important characteristic (its weight $=0.515$ ). The consistency index determines whether a pair comparison matrix is consistent or not. When the index is lower than 0.10, we conclude that the pair matrix is consistent (Saaty, 1980). When the index is larger than 0.10 , pairwise comparisons should be reconsidered.

Table 5. Pair comparison matrix among the four selected criteria.

\begin{tabular}{|l|c|c|c|c|c|}
\hline & Price & Mobility & Performance & Design & Weight \\
\hline Price & 1 & 5 & $1 / 2$ & 3 & 0.293 \\
\hline Mobility & $1 / 5$ & 1 & $1 / 7$ & $1 / 5$ & 0.050 \\
\hline Performance & 2 & 7 & 1 & 5 & 0.515 \\
\hline Design & $1 / 3$ & 5 & $1 / 5$ & 1 & 0.142 \\
\hline
\end{tabular}

Consistency index $=0.064$

The weight matrix for the four selected criteria is shown in Table 6 . The final results we obtained are as follows: final results $=$ the weight matrix for the four criteria (Table 5) times the weight matrix among the four criteria (Table 6). In this case, performance is the most important and price is somewhat less 
important. Because PC 13 is comparatively low priced, it was selected as the final choice (see Table 7).

Table 6. Weight matrix for the four selected criteria.

\begin{tabular}{|c|c|c|c|c|}
\hline & Price & Mobility & Performance & Design \\
\hline PC 11 & 0.125 & 0.056 & 0.222 & 0.369 \\
\hline PC 12 & 0.208 & 0.373 & 0.111 & 0.206 \\
\hline PC 13 & 0.562 & 0.090 & 0.222 & 0.109 \\
\hline PC 14 & 0.060 & 0.108 & 0.222 & 0.206 \\
\hline PC 15 & 0.045 & 0.373 & 0.222 & 0.109 \\
\hline
\end{tabular}

Table 7. Alternatives and final results of AHP for the task of buying a PC.

\begin{tabular}{|l|c|c|c|c|c|c|c|c|}
\hline & $\begin{array}{c}\text { CPU } \\
(\mathrm{GHz})\end{array}$ & $\begin{array}{c}\text { RAM } \\
(\mathrm{GB})\end{array}$ & $\begin{array}{c}\text { HDD } \\
(\mathrm{GB})\end{array}$ & $\begin{array}{c}\text { Monitor } \\
\text { (inches) }\end{array}$ & $\begin{array}{c}\text { Weight } \\
(\mathrm{kg})\end{array}$ & $\begin{array}{c}\text { Battery } \\
\text { (hours) }\end{array}$ & $\begin{array}{c}\text { Price } \\
(\text { yen) }\end{array}$ & Results \\
\hline PC 11 & 2.53 & 4 & 500 & 15.6 & 2.80 & 2.1 & 129,800 & 0.206 \\
\hline PC 12 & 2.53 & 4 & 500 & 14.1 & 2.50 & 3.9 & 122,280 & 0.166 \\
\hline PC 13 & 2.53 & 4 & 500 & 15.4 & 2.70 & 2.4 & 109,800 & $\underline{0.299}$ \\
\hline PC 14 & 2.53 & 4 & 500 & 16.4 & 3.20 & 3.0 & 141,871 & 0.167 \\
\hline PC 15 & 2.66 & 4 & 500 & 15.6 & 2.75 & 4.0 & 148,799 & 0.162 \\
\hline
\end{tabular}

\section{Conclusion}

In this study, we proposed a method of selecting alternatives from self-organizing product maps and making purchase decisions using AHP. In our proposed process, users will first look at the product map and confirm that they understand the primary features of the products in each cluster. Next, they will look at the component maps and confirm that they understand each component value. Then, they will identify a favorite cluster and/or a favorite component map and select alternatives to their original choices. We also showed several examples of selecting alternatives from the product map and making decisions using the relative measurement AHP. In our future work, we will apply our proposed method to other products and other types of AHP, including absolute measurement, inner dependence, outer dependence and innerouter dependence.

\section{REFERENCES}

Kinoshita, E. (2000). An Introduction to AHP (in Japanese). Nikkagiren, Tokyo.

Kohara, K., \& Isomae, M. (2006). Purchase decision support with self-organizing maps and analytic hierarchy process. In: Vale, Z., Ramos, C., \& Faria, L. (eds). Proceedings of International Conference on Knowledge Engineering and Decision Support, 151-157, Lisbon.

Kohara, K., \& Tsuda, T. (2010). Creating product maps with self-organizing maps for purchase decision making. Transactions on Machine Learning and Data Mining, 3, 2, 51-66.

Kohonen, T. (1995). Self-organizing maps. Springer, New York.

Saaty, T. (1980). The analytic hierarchy process. McGraw-Hill, New York. 